\title{
Public debt and economic growth in emerging market economies
}

\author{
Bettina Fincke and Alfred Greiner
}




\title{
Public debt and economic growth in emerging market economies
}

\author{
Bettina Fincke* Alfred Greiner*
}

\begin{abstract}
This paper studies the relationship between public debt and economic growth for selected emerging markets performing panel data estimations. Several regressor variables are included, but the main focus is on public debt. The results reveal a significant positive correlation between public debt and the subsequent growth rate of per capita GDP. Population and investment also yield a significant positive influence on subsequent growth, whereas the initial real GDP per capita gives a negative influence. Other variables such as the inflation rate, the trade balance or the exchange rate do not render a significant effect with respect to economic growth.
\end{abstract}

JEL: E62, H63

Keywords: Public Debt, Economic Growth, Emerging Markets, Empirics

*Department of Business Administration and Economics, Bielefeld University, P.O. Box 100131, 33501 Bielefeld, Germany, e-mails: bfincke@wiwi.uni-bielefeld.de (corresponding author), agreiner@wiwi.unibielefeld.de. 


\section{Introduction}

With the development of the current financial and economic crisis a great many economies around the world have been troubled by high and increasing public debt to GDP ratios. They root in high budget deficits due to decreasing tax revenues and increasing public expenditures. A lot of countries find themselves in a recession facing high unemployment and low production for instance. The GDP of many economies has declined sharply. Especially Europe, and in particular the Euro-Zone, was affected and many governments reacted with fiscal stimulus programs and financial support. Also, the banking sector had to be backed, for instance in Ireland and Spain. All these measures and instruments were costly and mainly financed by deficits.

However, not only Europe and other industrialized economies had been affected. Due to the tight economic interrelations and integration the crisis influenced several countries worldwide, among them also many emerging market economies. They are a group of ambitious countries characterized by a high economic growth performance. Thus, in times of the crisis, with the distinctive symptom of high deficits and increasing public debt, a central question regards the relationship between public debt and economic growth and how these interact in the context of emerging markets economies with their special attribute of a high growth performance.

Such a study is even more topical against the background of the recent developments: starting in 2013 and continued in 2014 many emerging market economies have found themselves in times of trouble. With a massive outflow of capital and a severe drop of currencies of emerging market countries, such as Brazil's Real, Thailand's Baht, the Turkish Lira or the South African Rand the economic situation worsened, see table 1. In January 2014 the Turkish central bank felt impelled to increase some of its short term interest rates up to 10 and $12 \%$ (from 4.5 and 7.75 respectively), for example, to countervail the falling of the Turkish Lira, cf. Reuters (2014). Recently, China's growth performance dropped from usually two-digit figures in the middle of the 2000s to about 
seven percent in 2012 (measured in terms of real GDP per capita, IMF (2014a) data). Thus, a closer study analyzing the relation between several (economic) variables and economic growth focusing on emerging market economies may provide additional insight, especially concerning the impact of public debt.

As regards the economics literature, there exist quite a many empirical studies, which analyze the relationship between public debt and economic growth. A frequently cited contribution is the one by Reinhart and Rogoff (2010) who find a threshold of public debt relative to GDP of about 90 percent beyond which the relationship between debt and growth becomes negative. Other studies support that outcome and detect an inverted Ushaped relation between debt and growth. For example, Checherita-Westphal and Rother (2012) perform regression analyzes for 12 euro area countries over the period 1970-2011, where they distinguish between annual growth rates and growth rates over a time span of 5 years. For both cases, these authors find an inverted U-shaped relation between debt and growth, with the threshold of public debt being at 70-80 percent of GDP. ${ }^{1}$ Recently, also Dreger and Reimers (2013) study the effect of the debt ratio on the real GDP growth rate for euro-area members and non-euro-area European economies. They distinguish between sustainable and non-sustainable debt states and also detect a negative effect of the debt ratio on economic growth.

While Reinhardt and Rogoff's (2010) work does include emerging market economies, the later two solely analyze European countries. Another study, which contains emerging market economies in their analysis, is the paper by Kumar and Woo (2010). They apply growth regressions with a 5-years-growth rate and reveal that there is a negative relationship between the debt to GDP ratio at the beginning of a period and the growth rate. They also estimate the relation between public deficits and economic growth and discover a negative correlation, too, and detect non-linearities in the relationship between deficits

\footnotetext{
${ }^{1}$ Earlier studies using time series data for the USA indicate a growth maximizing debt to GDP ratio around 40 to 50 percent, cf. Smyth and Hsing (1995) and the literature cited in that paper.
} 
and debt ratios and subsequent growth rates. For a survey of studies on the relationship between public debt and economic growth see Panizza and Presbitero (2013). They show that thresholds and, more generally speaking, a non-monotonic relationship between debt and growth, are sensitive to changes in data coverage and to the empirical techniques, which are applied and suggest to especially take cross-country heterogeneity into account.

With this study we intend to contribute to the empirical literature dealing with the relationship between public debt and economic growth, where we focus on emerging market economies. Our analysis is based on panel data estimations for eight selected countries.

The rest of the paper is organized as follows. In the next section, we first reflect on the specifics and the selection of emerging market economies. Section 3 describes the data set and the estimation method. Section 4 presents the results and section 5, finally, concludes.

\section{The specifics of emerging market economies}

Before studying the growth performance and its relation to public debt in emerging market economies we first present an appropriate demarcation and choice of the countries under consideration. Even though there are many approaches to classify the group of emerging market economies, there is no clear cut definition (see for instance Fornés and Butt Philip, 2012, chapt. 2). Without any doubt, an essential property characterizing emerging market economies is a high economic growth performance. Here, we decided to include eight different countries from various parts of the world. First, two Latin American economies, Brazil and Mexico, have been taken into account, which were both strongly affected by the debt crisis in Latin America in the 1980s (expressed in terms of low or even negative growth and strongly rising debt to GDP ratios). Further, representing the upcoming Asian market, four South Asian and Southeast Asian economies have been added, India, Indonesia, Malaysia and Thailand of which some had been hit by the Asian crisis in 
1997/1998. For example, the debt to GDP ratios almost tripled in Thailand (1996/1997) and in Indonesia (1997/1998). Both were bailed-out by large IMF rescue packages, cf. for instance Reinhart and Rogoff (2009). As an African nation, South Africa has been included whose economy strongly benefited from the abolishment of apartheid in the early 1990s. In terms of growth, its fluctuating low rates turned positive and took high values after apartheid had been overcome. As regards debt, it rescheduled and/or defaulted on its external debt in 1985, 1989 and 1993, cf. Reinhart and Rogoff (2009) Table 6.3. Finally, also Turkey has been selected, from a geographical point of view located both in Europe as well as in Asia, that also achieved high economic growth, especially in the middle to late 1990s.

Oftentimes, also Russia and China as two of the 'BRICS' states (ㅁazil, Russia, India,

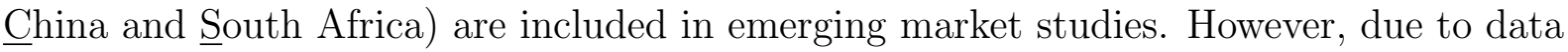
availability Russia and China are neglected in our study (some Russian time series only start in 1992 and some Chinese data are available only after the mid 1980s).

As mentioned above, a central characteristic of emerging market economies is their outstanding growth performance. To get a first visual impression of these magnitudes, figures 1 and 2 show the per capita GDP growth rates for the selected countries for the five-years and three-years sub-period, respectively. They are computed as the difference of the natural logarithm of real GDP per capita. ${ }^{2}$ In the figures, they are marked at the beginning of the intervals and give the economic growth for the following five or three years.

Figure 1 shows negative growth only for South Africa in the 1980s, which corresponds to the last years of the Apartheid regime and its debt crises mentioned above. Also, for Brazil in the late 1980s strong negative growth is observable, which reflects the Latin American debt crisis and the years of Brazil's hyperinflation. However, economic condi-

\footnotetext{
${ }^{2}$ For the data see IMF (2014a), OECD (2014) and World Bank (2014). All figures and estimations have been implemented in R 3.0.1. The plots are generated with scatterplot implemented in package car.
} 


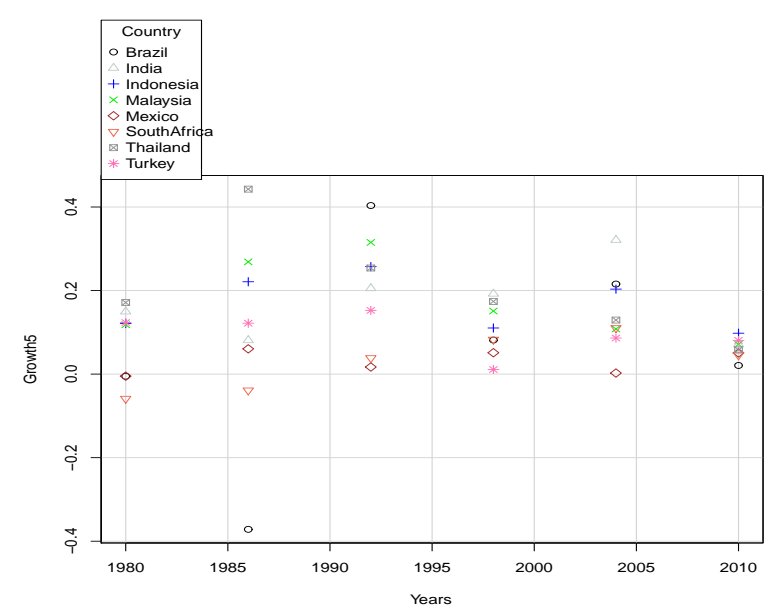

Figure 1: Five years growth.

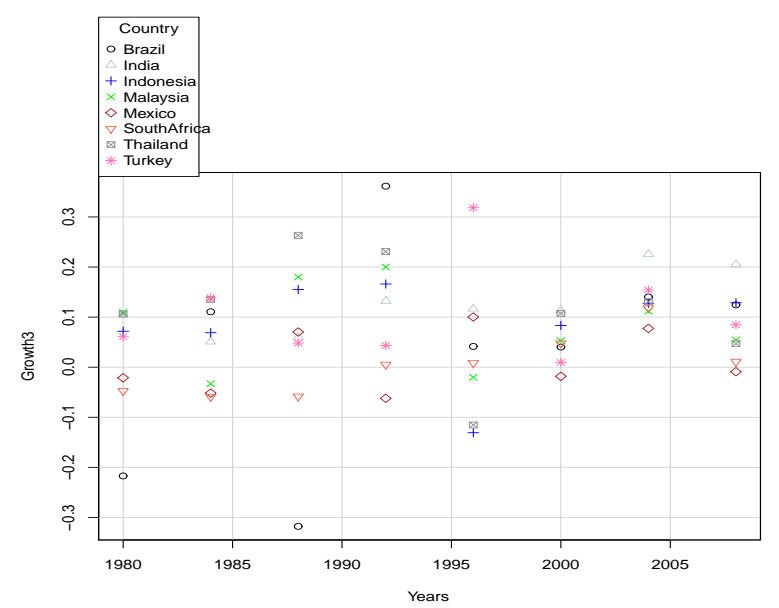

Figure 2: Three years growth

tions changed and improved, turning Brazil's growth rate to higher and positive values in the 1990s. This is confirmed by the three-years growth specification, depicted in figure 2. Again the partly strong negative growth performance of Brazil, South Africa and Mexico (who defaulted in 1982) in the 1980s becomes obvious and the comedown of the Indonesian and Malaysian economy during the Asian crisis in the late 1990s. Since this latter effect is only observable in the shorter interval (three-years period), the growth data for these two can be interpreted as an indication for highly dynamic and fast recovering economies. Noticeable in terms of high positive growth rates, as shown in figure 2, are the late 1990s for Turkey and the 2000s for India.

However, as mentioned in the introduction, many of these countries got into severe economic trouble recently. This is not only expressed in terms of a rapid drop in growth, shown in figures 1 and 2 above, which is certainly a result of the recent economic and financial crisis. In addition, one can also observe a severe decline in the currencies for some of them. Table 1 gives the exchange rates (relative to the euro) in 2013 and 2014 for the selected countries plus the US for comparison. ${ }^{3}$

Obviously, quite a lot of those currencies have fallen rapidly. There have been changes

\footnotetext{
${ }^{3}$ See ECB (2014) for the data (monthly frequency and end of period specification).
} 


\begin{tabular}{c|ccccccccc}
\hline Period & Brazil & Indonesia & India & Mexico & Malaysia & Thailand & Turkey & USA & South Africa \\
\hline 2013Mar & 2.57 & 12447.96 & 69.57 & 15.82 & 3.97 & 37.42 & 2.32 & 1.28 & 11.82 \\
2014Mar & 3.13 & 15663.17 & 82.58 & 18.02 & 4.50 & 44.71 & 2.97 & 1.38 & 14.59 \\
\hline
\end{tabular}

Table 1: Exchange rate development (2013-2014).

of about $20 \%$ and more for the Brazilian Real, for Thailand's Bhat, the Turkish Lira and for the South African Rand relative to the euro. Also, the Indonesian Rupiah and India's Rupee lost about $20 \%$ within the last year, whereas the US\$ changed by only $7 \%$. The reasons for that development are manifold, such as political and social events in Thailand for instance, and certainly the withdrawal of capital from those economies. Many emerging market countries find themselves in times of changing economic conditions right now. This is not a new phenomenon: Reinhart and Rogoff (2009) list, amongst others, the currency crisis in Mexico in 1994, Asia in 1997 and Brazil in 1999, whereat they define a currency crash as a depreciation of at least $15 \%$ per year. ${ }^{4}$

Thus, as the crisis seems to ease, a closer study of the economic situation and its development over the years with a special focus on economic growth and public debt is an interesting research question. Moreover, with the impressive feature of high economic growth rates in emerging market economies, is it possible to identify certain effects which have particularly influenced and determined that remarkable growth over the years?

\section{The data and the estimation procedure}

According to the demarcation above, we study the growth performance and its relation to public debt in emerging market economies for the eight countries Brazil, India, Indonesia, Malaysia, Mexico, South Africa, Thailand and Turkey. But, as pointed out in IMF (2003), there are enormous difficulties in data access for emerging market economies. Thus, data

\footnotetext{
${ }^{4}$ They point out that for more recent series a $25 \%$ benchmark may be appropriate, cf. Reinhart and Rogoff (2009) p. 5f. and their references. That would still be close to the changes in table 1.
} 
availability essentially determines the countries included in our study. Based on (almost) continuous data series covering the years from 1980 until 2012 for these eight countries a balanced panel set has been constructed, allowing an analysis of growth performance for over 30 years. Updating and including the 2012 observation enables also to study the effect of the global financial and debt crisis.

Following Kumar and Woo (2010), we separate non-overlapping intervals from the full time period. Here, two types of sub-periods are considered: five years $q=5$ and three years $q=3$. This means that we are interested in the question of how the public debt to GDP ratio at time $t-q$ affects the growth rate for the following five or three years, respectively. Consequently, for $q=5$ the six intervals cover (1980-1985), . , (2004-2009) and (2010-2012), where the last sub-period covers only two years. For $q=3$ the eight sub-periods start with (1980-1983) and end with (2008-2011). ${ }^{5}$

In order to interrelate the growth situation depicted in figures 1 and 2 with the debt position for the selected economies, figure 3 presents a first impression of the public debt situations over the time horizon under consideration. ${ }^{6}$

Here, the lines represent a nonparametric regression smooth (see for instance Fox et al., 2013) and may serve as a basic orientation, whereas the dots and crosses etc. represent the actual observations. As a general perception for most of the depicted emerging market economies, there seems to be some marked similarities, as the wavelike development shows: a distinctive peak of the debt to GDP ratios in the late 1980s, followed by a decline and another height shortly prior and around the year 2000. They reflect two periods of severe crises: the Latin American debt crisis of the 1980s and the Asian crisis in 1997/1998. For example, Brazil and Mexico heavily suffered from the Latin American debt crisis. Both countries participated in the Brady Plan for restructuring their public debt positions, which is also visible in figure 3 for the late 1980s. The effects of the Asian crisis are

\footnotetext{
${ }^{5}$ For a similar application to industrialized economies see Fincke and Greiner (2013).

${ }^{6}$ See Abbas et al. (2010) and IMF (2014b) for the data.
} 


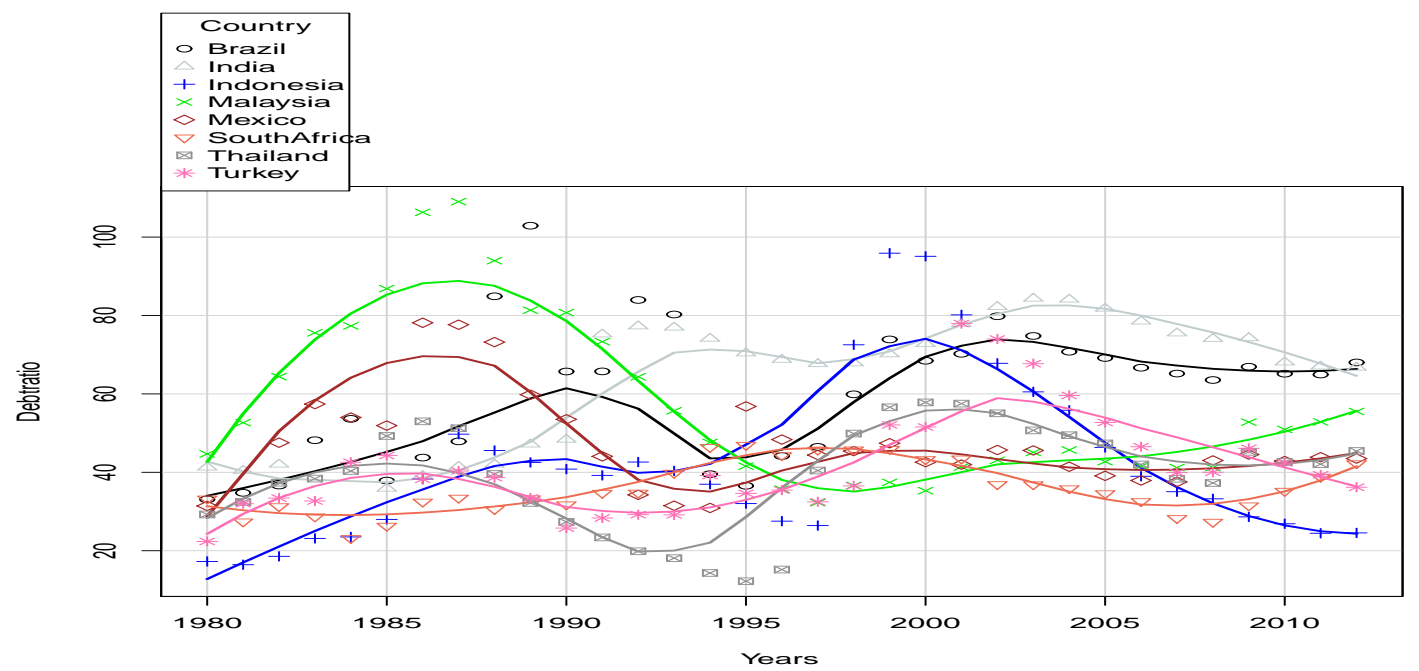

Figure 3: Debt to GDP ratio.

shown in the deteriorating debt situation of the south east Asian economies included in our study (except Malaysia), for instance Indonesia's and Thailand's debt almost doubled around that time. However, South Africa's debt ratio shows a contrary evolution, as the highest values appear in the middle of the 1990s, which may be explained by the political changes. Further, the effects of the current financial and debt crisis are visible in the most recent observations. ${ }^{7}$

To get a more profound idea about the relationship between public debt and economic growth, we estimate the following regression model, where we proceed as in Kumar and Woo (2010), Dreger and Reimers (2013) and Fincke and Greiner (2013),

$$
y_{i, t}-y_{i, t-q}=\phi_{0}+\phi_{1} b_{i, t-q}+\sum_{j} \phi_{j+1} Z_{j, i, t-q}+\epsilon_{i, t}
$$

where $y_{i, t}$ indicates the natural logarithm of real GDP per capita for country $i$ at time $t$. The variable $b$ represents the public debt to GDP ratio, the vector of the control variables is denoted by $Z$ and $\epsilon$ is the error term. All regressors are measured at the beginning of a period, that is at $t-q$. Such a specification enables to study the effect of the

\footnotetext{
${ }^{7}$ For a detailed discussion of different public debt situations and crises see Reinhart and Rogoff (2009).
} 
initial explanatory variable on economic growth in subsequent years. As control variables we include the initial real GDP per capita, $y_{i, t-q}$, expressed in ln units, foreign trade, Trade $_{i, t-q}$, measured by the external trade balance to GDP ratio (exports less imports), investment $I n v_{i, t-q}$, measured as gross fixed capital formation relative to GDP and the initial annual inflation rate, $\operatorname{Inf} l_{i, t-q}$. As mentioned in the introduction, exchange rate effects might matter. Thus, in order to account for these, $E x c h_{i, t-q}$ measures possible exchange rate influences. Most of the emerging market economies do not only have a considerable population size (for instance in 2012 India counts 1.236 billion inhabitants) and a higher population growth than most industrialized countries, but also a different structure. Whereas in many industrialized countries the working-age population (15-64 years) has declined since the 1980s, there is a strong and continuous rise of this share in emerging market economies. In order to capture both, the dynamics and the structure, we work with the broader concept of total population, which is captured by the variable $P_{o p}, t-q$ (measured in logarithms) and included in the regression, too.

As mentioned above, the availability of the data limits the data set in size and structure. In our study, it is composed of the annual observations for the eight emerging market economies Brazil, India, Indonesia, Malaysia, Mexico, South Africa, Thailand and Turkey covering the years from 1980 until 2012. Mainly, the data stem from IMF (2014a), such as the GDP, population, GDP deflator, imports, exports, exchange rates and investment. The public debt ratio data has been taken from Abbas et al. (2010), for 2012 the update is based on IMF (2014b). The data refers to general government gross debt. Due to data availability, for Brazil the real values have been calculated using the CPI of OECD (2014) and for Turkey the GDP deflator also comes from OECD (2014). The base year for the deflators is 2005, except for Turkey (1998) and Brazil (2000). The annual inflation series has been taken from World Bank (2014). Concerning Turkey, for most data we resort to World Bank (2014). Whenever possible the series have been cross-checked, for instance IMF (2014a) observations have been compared with World Bank (2014). Sel- 
domly missing values have been replaced and merged, once available, and provided that the neighboring values and series correspond. Still, despite this amendment, for India no value for the debt ratio in 1984 could be obtained. Therefore, the initial year for the second 3-years growth interval was set to 1985 for India, indicating that it only comprises two-years growth, that is (1985-1987) instead of (1984-1987). As concerns the exchange rates, they have been measured as national currencies per $\$$ US and as averages in annual frequency. Due to availability it is sometimes reflected as market rate, or principal or official rate (however, the data series codes suggest comparability). For Brazil the data series is only available since 1983. Thus, the 1st Brazilian growth interval uses the 1983 observation as a starting point.

Both growth rates $g_{y}$, that is the growth rates for the three-year interval and for the five-years time span, are determined as the difference in the natural logarithm of GDP per capita at the end of a period $(t)$ and the beginning of a period $(t-q)$, that is $g_{y}=\ln Y_{t}-\ln Y_{t-q}=y_{t}-y_{t-q}$.

\section{Results}

In order to study the effects and influences on economic growth in the eight selected emerging market economies from above, we follow Kumar and Woo (2010), Dreger and Reimers (2013) and Fincke and Greiner (2013) and estimate the following regression equation for the three-years growth $(q=3)$ and for the five-years growth $(q=5)$ interval according to equation (1):

$$
\begin{aligned}
y_{i, t}-y_{i, t-q}= & \phi_{0}+\phi_{1} b_{i, t-q}+\phi_{2} \text { Pop }_{i, t-q}+\phi_{3} y_{i, t-q}+\phi_{4} \operatorname{Inv}_{i, t-q}+\phi_{5} \text { Infl }_{i, t-q}+ \\
& \phi_{6} \operatorname{Trade}_{i, t-q}+\phi_{7} \text { Exch }_{i, t-q}+\epsilon_{i, t}
\end{aligned}
$$

with the variables corresponding to the explanations from above. Please note that all the regressors are measured at the beginning of a period, that is at $t-q$, which enables to study the effect of the initial explanatory variable on subsequent growth rates. The data 
for the selected countries set ranges from 1980 until 2012. The estimations have been implemented in R 3.1.0 with the package plm (see for instance Croissant and Millo, 2008, or Kleiber and Zeileis, 2008) or with a simple standard $l m$ regression. Table 2 presents the estimation outcomes for equation (2) with the 5-years-growth interval for the eight countries Brazil, India, Indonesia, Malaysia, Mexico, South Africa, Thailand and Turkey. As usual, the goodness of fit, $R^{2}$ (adj), and the Durbin-Watson test, $D W$, are given for each regression. The different model types, that is fixed effects and random effects, are displayed in the columns. Tests regarding the model suitability are presented at the end of the table. The Hausman Test is used to test the random effects model against the fixed effects model.

\begin{tabular}{c|cc} 
& fixed effects & random effects \\
\hline Constant & & -0.2341 \\
$b_{t-5}$ & $0.0028^{* *}$ & $0.0028^{* *}$ \\
Pop $_{t-5}$ & $0.4663^{* *}$ & -0.0141 \\
$y_{t-5}$ & $-0.3150^{* *}$ & 0.0140 \\
Inv $_{t-5}$ & $0.0078^{\bullet}$ & 0.0060 \\
Infl $_{t-5}$ & 0.0001 & 0.0002 \\
Trade $_{t-5}$ & -0.0003 & -0.0032 \\
$E x c h_{t-5}$ & $-1.48 \cdot 10^{-5}$ & $-8.56 \cdot 10^{-6}$ \\
\hline$R^{2}($ adj $)$ & 0.40 & 0.25 \\
$D W$ & 2.50 & 1.78 \\
\hline \hline & Hausman & Test \\
& $\chi^{2}=22.07$ & $\mathrm{p}$-val. $=0.0025$ \\
\hline \hline & Significance & levels \\
$* *(1 \%$ level $)$ & $*(5 \%$ level $)$ & $\bullet(10 \%$ level $)$ \\
\hline \hline
\end{tabular}

Table 2: Estimation results, $q=5$, eight countries $(\mathrm{N}=48)$. 
The results of the estimated coefficients show for the sample of the eight selected emerging market economies a small but positive effect of the debt ratio on the subsequent 5 -years growth rate, which is significant at the $1 \%$ level. This finding holds regardless of the applied model type, that is fixed effects or random effects. ${ }^{8}$ Moreover, in the fixed effects model the coefficients of the population, the initial real GDP per capita and the investments are statistically significantly correlated with economic growth. The effect of population is positive just like the influence of investments. ${ }^{9}$ In contrast, a higher initial real GDP per capita tends to reduce growth in the following five years. In addition, the estimation of that model reveals significant country effects for Indonesia and Malaysia (1\% significance level) as well as for Mexico, South Africa and Thailand ( $5 \%$ significance level). Finally, the Hausman test suggests that the fixed effects regression model represents the model that comes closer to the true data generating process and, therefore, seems to be more suitable.

Interpreting these findings yields some expected results in line with the literature, such as the positive effect of the investments/gross fixed capital formation, which tends to support the growth of an economy in the upcoming years, or the negative influence of the initial real GDP, which displays a tendency for lower growth. But, the positive effect of public debt on the subsequent five-years-growth is contrary to a lot of papers, which have recently revealed a negative relationship between the two variables. However, it should be kept in mind that many of those studies focus on industrialized economies, such as the Eurozone for instance, whereas our analysis concentrates on (selected) emerging market economies. Those emerging market economies are on the transition path, on which the relation between debt and growth may be different from that on the long-run balanced

\footnotetext{
${ }^{8} \mathrm{~A}$ significant (5\%) positive effect was also obtained with a pooled regression. But, due to the heterogeneity in the country data and the poor regression results, we do not estimate the pooled model.

${ }^{9}$ For the random effects model type, the p-value for $\phi_{4}$ is given by 0.108 , which misses the $10 \%$ reference level for significance only slightly.
} 
growth path. Further, many papers suggest an inverted U-shaped relationship between public debt and economic growth. Thus, our estimation results may suggest that the countries in our sample are below such a tipping point, beyond which the relationship turns negative.

In order to see whether the time span of the growth interval makes a difference, the following table presents the results of the implementation of the same regression (2) for the three-years interval. Table 3 summarizes the outcomes.

\begin{tabular}{c|cc} 
& fixed effects & random effects \\
\hline Constant & & 0.2150 \\
$b_{t-3}$ & $0.0015^{\bullet}$ & $0.0015^{\bullet}$ \\
Pop $_{t-3}$ & $0.4589^{* *}$ & $0.3161^{* *}$ \\
$y_{t-3}$ & $-0.2550^{* *}$ & $-0.1557^{*}$ \\
Inv $v_{t-3}$ & 0.0016 & -0.0009 \\
Infl $_{t-3}$ & $-1.91 \cdot 10^{-5}$ & $2.20 \cdot 10^{-5}$ \\
Trade $_{t-3}$ & 0.0010 & -0.0011 \\
$E x c h_{t-3}$ & $-1.77 \cdot 10^{-6}$ & $-2.17 \cdot 10^{-6}$ \\
\hline$R^{2}($ adj $)$ & 0.21 & 0.20 \\
$D W$ & 2.66 & 2.58 \\
\hline \hline & Hausman & Test \\
\hline \hline (1\% level $)$ & $*(5 \%$ level $)$ & $\bullet(10 \%$ level $)$ \\
\hline \hline
\end{tabular}

Table 3: Estimation results, $q=3$, eight countries $(\mathrm{N}=64)$.

The results of these estimations support the findings from above and indicate a statistically significant influence on the three-years growth rate for the debt ratio, the country's population, and the initial GDP per capita. However, the estimated coefficients are, com- 
pared to the significance levels from table 2, smaller and the debt ratio is only significant at the $10 \%$ level. Nevertheless, the three evidentiary effects support the findings from above for the eight selected economies, suggesting a positive correlation between the debt ratio and the population, on the one hand, and upcoming growth rates, on the other hand, whereas a higher initial real GDP per capita tends to lower subsequent growth rates. Moreover, the fixed effects model indicates country specific effects only for Indonesia and Malaysia, each significant at the $10 \%$ level. According to the test on model suitability, the fixed effects model now seems to be less adequate compared to the random effects model.

Summarizing our results from all four estimations, that is both distinctions (fiveyears and three-years growth) and the two model types fixed effects and random effects, there is the common significant effect of the debt to GDP ratio. It indicates that public debt seems to be positively correlated with subsequent economic growth, both for the subsequent five years as well as the following three years in the selected eight emerging market economies. This may seem odd against the recent findings in the economics literature and the experience with the current debt crisis in Europe for instance. However, many studies have detected an inverted U-shape relationship between the two variables. This may give rise to the conclusion that these eight countries have not reached the tipping point, beyond which the effect turns negative. And, in fact, the actual data may support this: ${ }^{10}$

\begin{tabular}{cccccccc}
\hline Brazil & Indonesia & India & Mexico & Malaysia & Thailand & Turkey & South Africa \\
\hline 61.0 & 41.7 & 64.9 & 47.4 & 57.2 & 39.1 & 41.7 & 35.0 \\
\hline
\end{tabular}

Table 4: Average debt ratios in emerging market economies (1980-2012) in \%.

These average debt to GDP ratios are mostly below those of industrialized countries over the same time span, such as France (59.4\%), Germany (55.4\%), Italy $(111.0 \%)$ or

\footnotetext{
${ }^{10}$ Data sources from above retained.
} 
the US (65.7\%). ${ }^{11}$ Actually, Italy's debt ratio has constantly been above $90 \%$ since 1986 . Thus, most of the debt ratios of the eight selected emerging market countries are below those of other countries, which can explain the reasoning behind the positive influence on growth in the emerging markets.

A different explication for the positive, although very low, coefficient of the debt to GDP ratio may be that those emerging market economies are on the transition path where GDP and other economic variables grow very fast. This stage of development, comparable to the after World War II period in Europe, is characterized by a high marginal product of capital, giving rise to high growth, and by an expanding public sector so that there can exist a positive correlation between debt and growth. For example, deficit financed public investment that increases public debt can raise the growth rate on the transition path implying a positive correlation between debt and growth.

Another effect on economic growth that we have identified is the positive influence of the population. Since many of the countries under consideration have a large and growing population, this effect is easily comprehensible, just like the negative effect of the initial GDP. The exchange rate does not yield a significant effect on subsequent growth. However, the highly topical troubles discussed in section 2 may be too recent and are not incorporated in our estimations since the data only comprise the years up to $2012 .^{12}$

\section{Conclusion}

This paper has studied the relationship between public debt and economic growth in eight selected emerging market economies, that is Brazil, India, Indonesia, Malaysia, Mexico, South Africa, Thailand and Turkey. As these are characterized by high economic growth, they may reveal additional insight in the growth determining factors. With respect to

\footnotetext{
${ }^{11}$ See OECD (2013) for the data.

${ }^{12}$ For further estimation results see the appendix.
} 
economic growth we have distinguished between two specifications, a five-years growth interval and a three-years time span. As concerns the regressors we have included several variables, such as population, initial GDP and investment, but the main focus is on the influence of public debt. The estimations have been implemented by performing panel studies with a fixed effects model, taking into account the country specifics, and a random effects model.

The results reveal a significantly positive, although very small, correlation between the public debt to GDP ratio and subsequent economic growth for both time intervals (5-years and 3-years), independent of the estimated model. This finding is in contrast to many of the existing literature that finds a negative relation between the two variables or an inverted U-shaped relationship. One possible explanation for that outcome is that emerging market economies are on the transition path that is characterized by high growth rates and by an expanding public sector that invests a lot in growth enhancing infrastructure. Further, since in most of the economies considered in our study the mean of the debt ratios is below the average of other countries, such as large European economies or the US, our outcomes may not be too surprising as these emerging market economies can be in a stage where the negative effects of public debt are not yet that drastic.

Further, population (and investment in the 5-years fixed effects model) yields a significant positive influence on growth, whereas the initial real GDP per capita indicates a negative influence on subsequent growth. Other variables such as the inflation rate, the trade balance and the exchange rate did not render a significant effect on economic growth in the eight countries of our sample.

As the graphics of the growth rates and the debt to GDP ratios above have shown, there is a strong heterogeneity in the countries that can be taken into account by fixed effects estimation, for example, that yields the largest goodness of fit. The selected countries in this paper present some of the emerging market economies which can depict only a few characteristic properties of such economies. To gain a broader overview the 
panel would need to be extended by including more emerging markets. That, however, must be left to future research due to the limited data availability at the moment.

\section{Data Sources}

Abbas, S.M. Ali, Nazim Belhocine, Asmaa El-Ganainy and Mark Horton (2010) "A Historical Public Debt Database", IMF Working Paper WP/10/245, Washington, DC. Data: Historical Public Debt Database, (This Version: September 2012), www.imf .org/ external/pubs/ft/wp/2010/data/wp10245.zip, access: Jan. 14th 2014.

ECB (European Central Bank) (2014) Statistical Data Warehouse, "Bilateral Exchange rates", http: //sdw.ecb. europa.eu/browse.do?node=2018794, access: Apr. 28th 2014.

IMF (2014a): "International Financial Statistics," Database via StatistikNetz.de, DSI Data Service and Information.

IMF (2014b): "World economic Outlook Database", October 2013, http://www.imf. org/external/pubs/ft/weo/2013/02/weodata/download.aspx, access: Jan. 22nd 2014, International Monetary Fund.

OECD (2014): "Economic Outlook Statistics and Projections", Economic Outlook No 94 dataset, OECD iLibrary, http://www. oecd-ilibrary.org/statistics, access: Jan. 13th 2014 and OECD selection via StatistikNetz.de.

OECD Databases (2013): "Economic Outlook Statistics and Projections" also "Fiscal Positions and Business Cylcles (historical ed.)," via StatistikNetz.de, DSI Data Service and Information.

World Bank (2014): "World Bank Selection", World Development Indicators, via StatistikNetz.de, DSI Data Service and Information. 


\section{References}

Checherita-Westphal, C. and P. Rother (2012) "The impact of high and growing debt on economic growth. An empirical investigation for the euro area." European Economic Review, Vol. 56, no. 7: 1392-1405.

Croissant, Y. and G. Millo (2008) "Panel Data Econometrics in R: The plm Package", Journal of Statistical Software Volume 27 (2) http://www.jstatsoft.org/

Dreger, C. and H.-E. Reimers (2013) "Does Euro Area Membership Affect the Relation between GDP Growth and Public Debt?" Journal of Macroeconomics, available online 22 August 2013 and DIW Discussion Paper 1249, 2012.

Fincke, B. and A. Greiner (2013) "On the relation between public debt and economic growth: An empirical investigation" Bielefeld Working Papers in Economics \& Management No. 24-2013, http://ssrn. com/abstract=2362788.

Fornés, G. and A. Butt Philip (2012) "The China-Latin America Axis: Emerging Markets and the Future of Globalisation", Palgrave Macmillan, New York.

Fox, C., S. Weisberg, D. Adler, D. Bates, G. Baud-Bovy, S. Ellison, D. Firth, M. Friendly, G. Gorjanc, S. Graves, R. Heiberger, R. Laboissiere, G. Monette, D. Murdoch, H. Nilsson, D. Ogle, B. Ripley, W. Venables, and A. Zeileis, R-Core (2013) "Package car", http://cran.r-project.org/web/packages/car/car.pdf, last access on November 6th, 2013.

IMF (2003) International Monetary Fund, World Economic Outlook, September 2003, Chapter III Public Debt in Emerging Markets: Is it too high? http://www.imf. org/external/pubs/ft/weo/2003/02/pdf/chapter3.pdf, access: May 23nd 2014, International Monetary Fund. 
Kleiber, C., and A. Zeileis (2008) Applied Econometrics with R. Use R! Springer, New York.

Kumar, M.S. and J. Woo (2010) "Public debt and growth." IMF working paper number $W P / 10 / 174$.

Panizza, U. and A.F. Presbitero (2013) "Public debt and economic growth in advanced economies: A Survey", Swiss Journal of Economics and Statistics, Vol. 149, no. 2: $175-204$.

Reinhart, C.M. and K.S. Rogoff (2009) This Time is Different, Eight Centuries of Financial Folly. Princeton University Press, Princeton, New Jersey.

Reinhart, C.M. and K.S. Rogoff (2010) "Growth in a time of debt." NBER working paper number 15639.

Reuters (2014) "Turkish central bank makes massive rate hikes to stem lira fall." (By Seda Sezer and Daren Butler), http://www.reuters.com/article/2014/01/ 28/us-turkey-centralbank-rates-idUSBREA0R1W420140128, access: April, 26th 2014 .

Smyth, D.J. and Y. Hsing (1995) "In search of an optimal debt ratio for economic growth." Contemporary Economic Policy, Vol. 13, no. 4: 51-59.

\section{Appendix}

This appendix presents additional estimation outcomes including the variable government consumption, GCons, with the data for GCons again from IMF (2014a).

The outcomes in these tables mainly confirm the results from above. However, for $q=3$ the coefficient of the debt ratio becomes insignificant. But, it should be pointed out that in the random effects model (again the better model according to the Hausman test) 


\begin{tabular}{c|cc} 
& fixed effects & random effects \\
\hline Constant & & -0.2768 \\
$b_{t-5}$ & $0.0025^{* *}$ & $0.0027^{*}$ \\
Pop $_{t-5}$ & $0.4226^{* *}$ & -0.0114 \\
$y_{t-5}$ & $-0.3076^{* *}$ & 0.0138 \\
Inv $_{t-5}$ & $0.0088^{\bullet}$ & 0.0064 \\
$G C o n s_{t-5}$ & 0.0078 & 0.0023 \\
Infl $_{t-5}$ & 0.0002 & 0.0002 \\
$\operatorname{Trade}_{t-5}$ & 0.0015 & -0.0029 \\
$E x c h_{t-5}$ & $-1.09 \cdot 10^{-5}$ & $-7.63 \cdot 10^{-6}$ \\
\hline$R^{2}(\mathrm{adj})$ & 0.40 & 0.24 \\
$D W$ & 2.56 & 1.81 \\
\hline \hline & Hausman & Test \\
\hline \hline & $\chi^{2}=36.07$ & $\mathrm{p}-\mathrm{val} .=1.70 \cdot 10^{-5}$ \\
\hline \hline (1\% level $)$ & $*(5 \%$ level $)$ & $\bullet(10 \%$ level $)$ \\
\hline \hline
\end{tabular}

Table 5: Estimation results, $q=5$, eight countries $(\mathrm{N}=48)$ incl. GCons.

the p-value of the debt ratio (0.1567) is quite close to the value indicating significance at the $10 \%$ level. 


\begin{tabular}{c|cc} 
& fixed effects & random effects \\
\hline Constant & & 0.0969 \\
$b_{t-3}$ & 0.0012 & 0.0012 \\
Pop $p_{t-3}$ & $0.4114^{* *}$ & $0.2287^{*}$ \\
$y_{t-3}$ & $-0.2499^{* *}$ & $-0.1233^{\bullet}$ \\
Inv $_{t-3}$ & 0.0036 & 0.0006 \\
$G C o n s_{t-3}$ & 0.0105 & 0.0118 \\
Infl $_{t-3}$ & $-1.36 \cdot 10^{-6}$ & $5.42 \cdot 10^{-5}$ \\
Trade $_{t-3}$ & 0.0038 & 0.0014 \\
$E x c h_{t-3}$ & $2.66 \cdot 10^{-6}$ & $2.62 \cdot 10^{-6}$ \\
\hline$R^{2}($ adj $)$ & 0.23 & 0.21 \\
$D W$ & 2.81 & 2.72 \\
\hline \hline & Hausman & Test \\
\hline$*(1 \%$ level $)$ & $*(5 \%$ level $)$ & $\bullet(10 \%$ level $)$ \\
\hline \hline
\end{tabular}

Table 6: Estimation results, $q=3$, eight countries $(\mathrm{N}=64)$ incl. GCons. 